\title{
The Taiwan Society of Cardiology
}

\author{
Jyh-Hong Chen, MD, PhD
}

Dear Colleagues,

The Taiwan Society of Cardiology (TSOC) is a nonprofit medical society established on 7 May, 1960 with Professor Nong Ting as the founding president. The Society aims to connect cardiologists both here in Taiwan and worldwide in promoting research, education, prevention and application of cardiovascular medicine. Over the past 51 years, under the strong leadership of its presidents [Professor Nong Ding (1960-1984), Professor Hung-Chi Lue (1984-1987), Professor Benjamin N. Chiang (1987-1990), Professor Wen-Pin Lien (1990-1993), Professor Mau-Song Chang (1993-1995), Professor Shyh-Ming Shieh (1995-1997), Professor Philip Yu-An Ding (1997-1999), Professor Yung-Zu Tseng (1999-2001), Professor Chi-Woon Kong (2001-2003), Professor Yuan-Teh Lee (2003-2005), Professor ChengWen Chiang (2005-2007), Professor Fu-Tien Chiang (2007-2010) and current president Professor Jyh-Hong Chen (2010-2012)], the TSOC has grown and accomplished many targets, not just promoting the professional development of Taiwanese cardiologists but also providing the opportunity for members to interact internationally, playing an important role in the international cardiology arena. To date, the TSOC has more than 1,500 members, consisting of 170 ordinary members and 1,421 specialist members of which there are 1,224 adult cardiologists, 215 cardiac surgeons and 152 pediatric cardiologists. The Society bestows credentials upon cardiovascular specialists who meet its stringent qualifications.

\section{Mission of the TSOC}

Our mission is to promote cardiovascular research, and gather information on developments both locally and internationally in cardiovascular treatment and research to provide the most up-to-date information for members, in addition to organizing academic lectures and forums (Figure 1). The Society also regulates cardiovascular medical terms and standards, and publishes the official journal of the TSOC (Acta Cardiologica Sinica). The recognition and rewarding of those who contribute or make an outstanding achievement in the field of cardiology is also very important, together with accreditation of cardiology specialist board examinations, cardiology specialist guidance teachers and cardiology specialist teaching hospitals. We assist government formulation of health policy, standards, guidelines and ensure execution of other tasks and objectives as set by our charter.

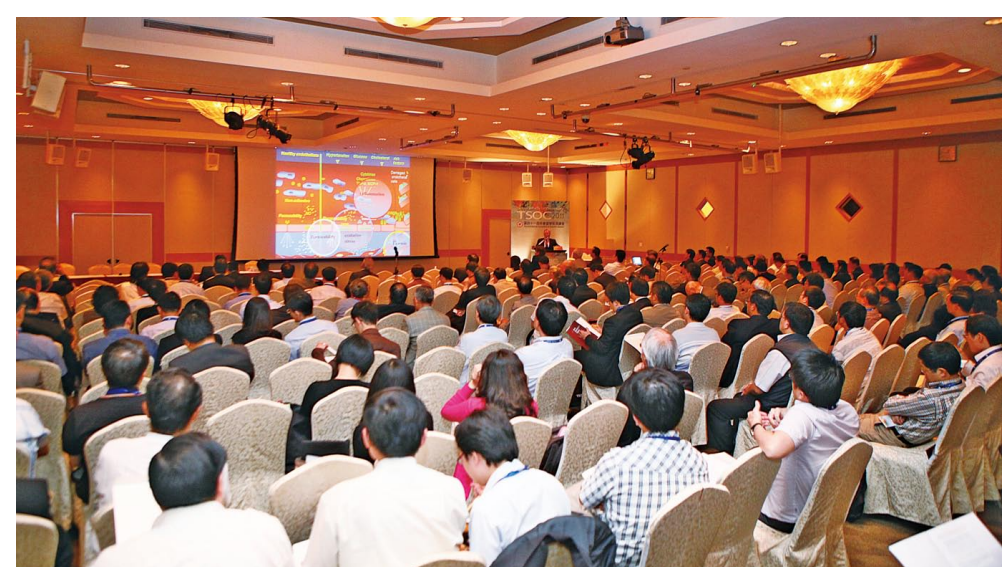

Figure 1. A lecture at the $41^{\text {st }}$ Annual Convention and Scientific Session of the Taiwan Society of Cardiology, 2011.

Released online February 7, 2012

Mailing address: Jyh-Hong Chen, MD, PhD, FACC, Professor of Medicine, National Cheng Kung University, No.1, University Road,

Tainan City 701, Taiwan (R.O.C.). E-mail: jyhhong@mail.ncku.edu.tw

ISSN-1346-9843 doi:10.1253/circj.CJ-88-0030

All rights are reserved to the Japanese Circulation Society. For permissions, please e-mail: cj@j-circ.or.jp 




\section{Committees of the TSOC}

At present there are 17 committees in the TSOC, comprising the committees for accreditation, editorial, academia, research, quality of care and policy, prevention, cardiac surgery, pediatric cardiology, international affairs and public relations, finance, interventional cardiology, electrophysiology and pacemaker, critical care, cardiac imaging, hypertension, heart failure, medical education and ethics. These committees span the breadth of cardiovascular care, and meetings are held regularly to discuss issues pertaining to the interest of each committee, with the aim of identifying and resolving problems by providing solutions and the effective execution of decisions made.

\section{Important Milestones in the History of the TSOC}

After the founding of TSOC in 1960, it soon became one of the first members of the Asian Pacific Society of Cardiology (APSC) and joined the International Society and Federation of Cardiology, now known as the World Heart Federation (WHF) in 1961. Realizing the importance of enhancing the quality of health care by certifying cardiologists and subspecialists who demonstrate the knowledge, skills, and attitudes essential for excellent patient care, the Cardiology Board Examination system was established in 1981, with the addition of the Cardiovascular Interventional Specialist Board Exam in 2007. Becoming an active member in international activities, it was an honor to host the $8^{\text {th }}$ Asian Pacific Congress of Cardiology in 1981, the $3^{\text {rd }}$ International Congress on Cardiovascular Disease in 2004, and both the $3^{\text {rd }}$ Asian Pacific Atrial Fibrillation Symposium and the $16^{\text {th }}$ Asian Pacific Congress of Cardiology in 2007. Our honorary president, Professor Nong Ting, was elected president of the WHF in 1985; in the same year, Acta Cardiologica Sinica was first published. Recognizing the importance of encouraging cardiologists to further research development and reward those with talent and achievements, the Nong Ting Award was established in 1985 and the Young Investigators Award was established in 1994, with setting up of the Research Fund in 2001, awarding those achieving the highest distinction in the field of cardiology. Dedicated to lifelong learning, the TSOC delivers the most current cardiovascular knowledge through a continuing medical education program, which was started in 1999, providing a variety of programs and products tailored to the needs of members in a variety of specialty areas at all stages of their careers. In addition, over the years a number of publications have been published, such as the "English-Chinese Dictionary of Cardiovascular Medicine" in 1994, and by incorporating the best of evidence-based science in cardiovascular medicine, other publications have been made available such as the "Emergency Cardiac Care Handbook" in 1995, the "Fundamental Critical Care Support Series" in 1998, the "Heart Patient Guidelines", "ST Elevation Myocardial Infarction Treatment Guidelines" in 2007 and the "Diabetes and Cardiovascular Guidelines" in 2009. In order to define the "gaps" between evidence and practice in our population, in 2008 the Acute Coronary Syndrome-Full Spectrum Registry was launched and in 2010 the ICD/CRT Registry was launched. In 2008, TSOC joined the European Society of Cardiology as an affiliated member and has since participated in many of their events, including academic and humanitarian (Figure 2).

\section{Official Journal}

As the official journal of the TSOC, Acta Cardiologica Sinica publishes peer-reviewed articles on all aspects of cardiovascular disease and basic science, including original clinical or experimental studies, review articles, case reports, short reports and letters to the editor. It also publishes abstracts of reports to be presented at the Annual Scientific 
Sessions of the Society. Acta Cardiologica Sinica (ISSN 1011-6842) is indexed in Excerpta Medica/ EMBASE and is issued quarterly. Since December 2007, it has been listed on the Science Citation Index Expanded.

\section{Contact Information for the TSOC}

Mailing address: 13F-1, No. 11, Min-Chuan West Road, Taipei 10452, Taiwan.

Tel: 886-2-25976177 9 ext.12 (Lynn), 16 (Emily), 17 (Sivic)

Fax: 886-2-25976180

E-mail: tsoc@tsoc.org.tw

Website: http://www.tsoc.org.tw

\section{Partnership Between the TSOC and the Japanese} Circulation Society (JCS)

The TSOC has enjoyed a close relationship with the JCS, as both societies promote the development of further cardiology research, training and exchange in the Asia-Pacific. Under the invitation of the JCS, we have recommended young investigators for the APSC oral/poster sessions at the Annual Scientific Meetings of the JCS. Subsequently at the $41^{\text {st }}$ Annual Convention and Scientific Session of the TSOC, we also invited other societies to recommend candidates for the International Young Investigator Award (Figure 3). It is our hope to continue maintaining this friendship, and enhance further communication and partnership with the JCS. We sincerely thank the JCS for the opportunity to introduce the TSOC in the Circulation Journal.

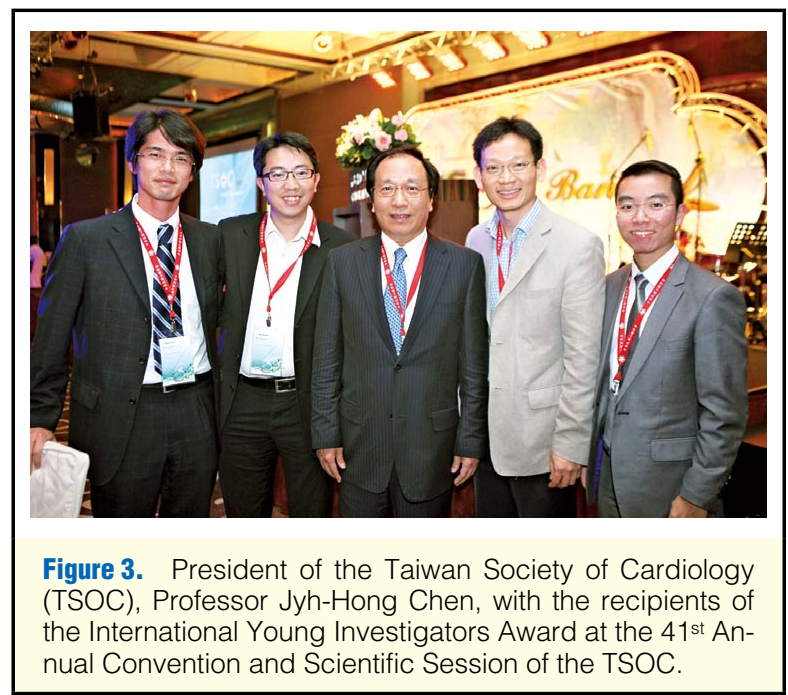

Jyh-Hong Chen, MD, PhD

President

Taiwan Society of Cardiology

(National Cheng Kung University)

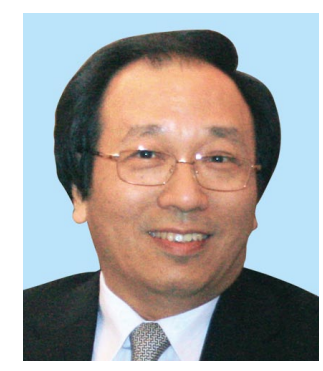

\section{Circulation Journal}

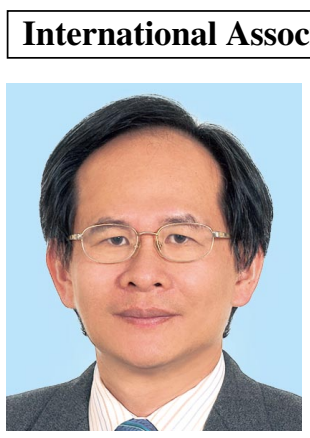

Shih-Ann Chen, MD

(National Yang Ming University)
On behalf of the Japanese Circulation Society, I deeply appreciate the great contribution of the Taiwanese cardiologists to the Circulation Journal.

Hiroaki Shimokawa, MD, $\mathrm{PhD}$

Editor-in-Chief

Circulation Journal 